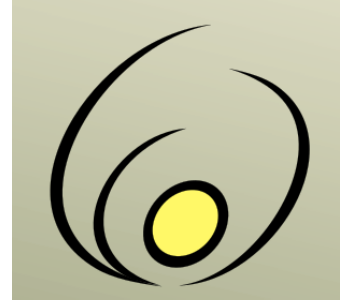

Fórum de Pró-Reitores de Extensão das Instituições Públicas de

Educação Superior Brasileiras

\section{Revista Brasileira de Extensão Universitária}

v. 11 , n. 3 , p. $361-376$, set.-dez. 2020

e-ISSN 2358-0399

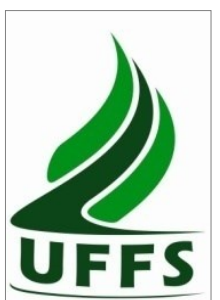

Content shared under Creative Commons Attribution 4.0 Licence CC-BY

\title{
Formação continuada em neurociência: percepções de professores da educação básica
}

\author{
Karine Ramires Lima ${ }^{1}$ (D) Luiza Freitas Lopes ${ }^{1}$ iD, Náthaly Marks Soares ${ }^{1}$, Ronan Moura Franco ${ }^{1}$, Elena \\ Maria Billig Mello ${ }^{1}$, Pâmela B. Mello-Carpes ${ }^{2}$
}

Resumo: O conhecimento básico sobre a neurociência é importante em diversos aspectos da vida, já que permite o entendimento de processos neurais presentes em nosso dia a dia, como a cognição e a aprendizagem. Para o professor, principal mediador da construção do conhecimento na sala de aula, o conhecimento desta temática é importante para facilitar sua prática pedagógica, já que a neurociência contribui para a compreensão dos processos cognitivos e das individualidades de cada aluno. O objetivo deste estudo é relatar a percepção e o conhecimento de professores da Educação Básica do município de Uruguaiana/RS acerca da neurociência e sua importância para a educação, antes e após a realização da oitava edição do curso de formação continuada intitulado "Curso de Neurociência Aplicada à Educação". No total, vinte e oito (28) professores participaram do curso, que abordou diferentes temas: neurociência e educação, neuroanatomia, neurofisiologia, neurobiologia da aprendizagem e memória, fatores que interferem na aprendizagem e inovação pedagógica. De acordo com a percepção dos professores, o curso ministrado foi de fundamental importância para a aquisição de novos conhecimentos sobre a neurociência, e todos concordaram que os conceitos abordados podem ser aplicados para melhorar sua prática pedagógica e seu ambiente de ensino.

Palavras-chave: Aprendizagem; Ensino; Cérebro; Professor

\section{Continuing training in neuroscience: perceptions of basic education teachers}

Abstract: Basic neuroscience knowledge is important in all aspects of life, as it allows the understanding of neural processes present in our daily lives, such as cognition and learning. For the teacher, the central mediator of knowledge in the classroom, it is essential to understand this theme since it can facilitate his pedagogical practice since neuroscience teaches to understand the student through their individualities. This study aims to report the perception and knowledge of primary education teachers in Uruguaiana, Rio Grande do Sul state, Brazil, about neuroscience, before and after the eighth edition of the continuing education course entitled "Course of Neuroscience Applied to Education." In total, twentyeight (28) teachers participated in the course, divided into two modules that addressed different themes: neuroscience and education, neuroanatomy, neurophysiology, the neurobiology of learning and memory, factors that interfere in learning, and pedagogical innovation. According to the teachers' perception, the course taught was of fundamental importance for acquiring new knowledge about neuroscience, and everyone agreed on the possible applicability of the concepts covered to improve their pedagogical practice and their teaching environment.

Keywords: Learning; Teaching; Brain; Teacher
Originais recebidos em

16 de maio de 2020

Aceito para publicação em

16 de setembro de 2020

1

Programa POPNEURO. Universidade Federal do Pampa (UNIPAMPA), campus Uruguaiana

2

Programa POPNEURO. Universidade Federal do Pampa (UNIPAMPA), campus Uruguaiana

panmello@hotmail.com

(autora para correspondência) 


\section{Introdução}

Nos dias atuais, a educação tradicional, na qual o professor é o único detentor do conhecimento, tem dado lugar a uma educação mais reflexiva, onde o aluno também ganha papel ativo no processo de ensinoaprendizagem (Cardoso \& Queiroz, 2019). Com isso, como membro importante para a construção do conhecimento, o professor deve estar capacitado para melhor compreender as necessidades dos seus alunos, o que exige destes profissionais o constante aperfeiçoamento de suas práticas pedagógicas (Escribano, 2007; Cardoso \& Queiroz, 2019).

Os professores possuem a tarefa de planejar estratégias metodológicas que melhor se adaptem ao contexto educativo abordado (Ricoy \& Couto, 2011). Ainda, possuem um papel imprescindível na construção do senso crítico e reflexivo de seus alunos (Bulgraen, 2010). Mais que isso, pode-se resumir que "o professor tem o dever de preparar os estudantes para pensar" (Fonseca, 1998). A partir disto, considerando que a neurociência abrange um conjunto de temas que estudam o sistema nervoso (Relvas, 2012), dentre eles os mecanismos da atenção, a aprendizagem e memória, a emoção, a linguagem e a comunicação (Ventura, 2010), estudar esta temática auxilia na compreensão dos processos cognitivos e de aprendizagem e, consequentemente, na atuação pedagógica do professor.

Entender a neurociência, enfatizando a sua aplicabilidade para a educação (neuroeducação), é uma subárea ainda recente, que busca aplicar os conhecimentos do sistema nervoso sobre os processos biológicos da aprendizagem na prática educacional. Este conhecimento é fundamental para o trabalho do professor, pois permite o desenvolvimento de novas estratégias pedagógicas, objetivando otimizar o processo de aprendizado dos estudantes (Blakemore \& Frith, 2000). Entretanto, na formação inicial dos professores esta temática ainda é pouco presente (Cardoso \& Queiroz, 2019), déficit que pode ser revertido através de cursos de formação continuada, especialização ou pós-graduação, impactando positivamente na atuação docente (Filipin et al., 2017).

O conhecimento da neurociência possibilita ao professor a atribuição da ciência básica sobre o cérebro e seu funcionamento, relacionando a teoria neurocientífica com a sua prática em sala de aula e os conhecimentos educacionais, o que facilita o entendimento do processo ensino-aprendizagem e contribui para um desenvolvimento pedagógico qualificado (Silva \& Morino, 2012; Cardoso \& Queiroz, 2019). Adicionalmente, tal conhecimento desenvolvido em espaços acadêmicos soma vários aspectos positivos, uma vez que possibilita ao docente compreender as variadas formas de aprender e ensinar, proporcionando uma nova visão metodológica para a formação discente (Cardoso \& Queiroz, 2019).

Nesse sentido, o objetivo deste estudo é relatar a percepção e o conhecimento de professores da Educação Básica (EB) do município de Uruguaiana/RS acerca da neurociência, antes e após a realização da oitava edição do curso de formação continuada intitulado "Curso de Neurociência Aplicada à Educação".

\section{Materiais e métodos}

\section{Curso}

O objetivo geral do curso, que é promovido anualmente em Uruguaiana/RS, é promover a formação de professores da EB em neurociência. A oitava edição do "Curso de Neurociência Aplicada à Educação" ocorreu no mês de outubro de 2019, sendo dividido em dois módulos que abordaram as seguintes temáticas: diálogos entre a neurociência e a educação; neuroanatomia e; neurofisiologia (módulo 1); neurobiologia da aprendizagem e memória; fatores que interferem na aprendizagem e; inovação pedagógica e a neurociência 
(módulo 2). Cada módulo teve duração de 3 turnos, sendo cada temática abordada em um período médio de 3,5 horas, totalizando cerca de $20 \mathrm{~h}$ de atividades presenciais. O curso foi oferecido aos professores da comunidade gratuitamente. Em cada aula foram realizadas explanações teóricas, seguidas de atividades práticas e discussão em grupo. A seguir, destacamos as aulas e os principais pontos abordados durante os módulos.

\section{Participantes}

A divulgação do curso foi realizada nas redes sociais do Programa POPNEURO ${ }^{1}$ da UNIPAMPA (promotor do curso), seguida pela abertura do período para inscrição, realizada através do preenchimento de um formulário online. Foram ofertadas 40 vagas e os critérios de inclusão basearam-se no público a que se destina esta ação: professores de EB.

Recebemos 89 inscrições e 40 professores foram selecionados, de acordo com a ordem de inscrição. Uma lista de suplentes foi divulgada, e estes foram chamados à medida que algum dos selecionados desistisse do curso. Dentre os 40 professores homologados na lista final, 28 participaram dos dois módulos ofertados durante o curso, cumprindo pelo menos $75 \%$ da carga horária total. Entre os participantes, 26 eram mulheres e 2 eram homens, com a média de idade de $36 \pm 7$ anos. A Tabela 1 descreve suas características em termos de formação e atuação docente, obtidas através do formulário de inscrição online.

O VIII Curso de Neurociência Aplicada à Educação teve suas aulas ministradas pelos componentes da comissão organizadora (membros da equipe do Programa POPNEURO) e alguns colaboradores, sendo 4 professores com experiência nas áreas de neurociência e/ou educação (um deles o professor coordenador); três alunos de pós-graduação da área de Ciências Biológicas, e quatro alunos de graduação dos cursos de Fisioterapia e Enfermagem.

Tabela 1. Características em termos de formação e atuação docente dos participantes do VIII Curso de Neurociências Aplicada à Educação. Expresso em percentual (\%), $n=28$. (EF = ensino fundamental.).

\begin{tabular}{|c|c|c|c|c|c|c|c|}
\hline \multicolumn{8}{|c|}{ Formação e atuação docente } \\
\hline & & & & Modalidade & & Atuação & \\
\hline Formação & $\%$ & Etapa & $\%$ & da escola & $\%$ & (anos) & $\%$ \\
\hline Pedagogia & 54 & Pré-escola & 18 & Municipal & 50 & 1 a 5 & 36 \\
\hline Letras & 10 & $E F$, séries iniciais & 29 & Estadual & 18 & 6 a 10 & 36 \\
\hline Educação Física & 7 & $E F$, séries finais & 29 & Particular & 32 & $>10$ & 28 \\
\hline Matemática & 7 & Ensino médio & 11 & & & & \\
\hline Ciências da Natureza & 7 & Coordenação & 13 & & & & \\
\hline História/Geografia & 7 & & & & & & \\
\hline Educação Especial & 4 & & & & & & \\
\hline Artes Visuais & 4 & & & & & & \\
\hline Pós-Graduação & 50 & & & & & & \\
\hline
\end{tabular}


Tabela 2. Questionário inicial.

\section{Contato com o tema}

Já fez algum curso na área de educação e neurociência? ( ) Sim （ ） Não

Costumar ler sobre neurociência e educação? ( ) Sim ( ) Não

Tem contato com temas relacionados à neurociência pelas redes sociais?

( ) Sim, por Facebook ( ) Sim, por Instagram ( ) Nunca tive contato ( ) Outro

\section{Conhecimentos prévios}

De uma escala de 0 (ruim) a 10 (excelente), qual nível de conhecimento você considera ter acerca dos temas:

( ) Neuroanatomia

( ) Neurofisiologia

( ) Neurobiologia da aprendizagem e memória

( ) Inovação pedagógica e neurociência

O que você entende por neurociência?

\section{Motivações e perspectivas}

Em sua opinião, qual a importância de estudar neurociência aplicada à educação?

O que the motivou a se inscrever neste curso?

Quais são as suas perspectivas acerca deste curso?

Tabela 3. Questionário final.

\section{Relevância do curso}

O curso realizado atendeu suas expectativas? Comente.

Comente os principais pontos positivos e negativos do curso.

\section{Principais aprendizados}

De uma escala de 0 (ruim) a 10 (excelente), qual nível de conhecimento você considera ter acerca dos temas:

( ) Neuroanatomia

( ) Neurofisiologia

( ) Neurobiologia da aprendizagem e memória

( ) Inovação pedagógica e neurociência

O que você entende por neurociência?

Seu entendimento nesta área melhorou após a realização do curso?

Os conhecimentos a partir deste curso irão impactar na sua prática docente? Comente.

\begin{tabular}{l} 
Outras observações \\
\hline O que você mais gostou no curso? \\
Qual o maior aprendizado adquirido a partir do curso? \\
Considerando uma escala de 0 (ruim) a 10 (excelente), atribua uma nota ao curso realizado. \\
Se você tiver observações, sugestões ou comentários adicionais a nossa equipe, por favor, forneça-os \\
neste espaço.
\end{tabular}




\section{Módulo 1}

\section{a) Diálogos entre a neurociência e a educação}

Explanação teórica: os alunos foram apresentados ao objetivo do curso e puderam inicialmente conhecer a história do grupo envolvido na organização do curso. Foram introduzidos os conceitos de neurociência e sua importante implicação no âmbito da educação, discutindo sua relação direta durante o processo de ensinoaprendizagem. A última parte da explanação contou com o relato de algumas experiências vivenciadas pela coordenadora do curso quando atuou junto ao Escritório Internacional de Educação da UNESCO, em Genebra/Suíça, no Programa Science of Learning, abordando como o conhecimento da neurociência pode contribuir com o desenvolvimento da educação.

Atividade(s) prática(s): duas atividades foram propostas e aplicadas em diferentes momentos.

i. "O que é neurociência?": antes de introduzir os conceitos de neurociência, os alunos foram questionados sobre o que eles já conheciam sobre o tema. Para esta atividade, cada aluno recebeu um "post it" onde foi orientado a escrever uma palavra que remetesse à neurociência. Cérebro, aprendizagem e memória foram as palavras mais citadas. A atividade foi seguida por discussão da temática.

ii. "Desvendando neuromitos": cada aluno recebeu uma série de afirmações relacionadas ao funcionamento do sistema nervoso que, após ler atentamente, deveriam indicar uma das alternativas: "concordo", "discordo" ou "não sei opinar". As afirmações foram sendo discutidas ao longo da aula. O principal objetivo foi desmistificar informações que são comumente popularizadas de forma equivocada sobre a neurociência, também chamadas de "neuromitos".

\section{b) Neuroanatomia}

Explanação teórica: o sistema nervoso foi inicialmente conceituado de forma geral, abordando sua organização (sistema nervoso central e periférico). Para o sistema nervoso periférico, ressaltou-se os nervos espinais, receptores periféricos, nervos cranianos, além de abordar sobre o sistema nervoso autônomo/visceral. 0 sistema nervoso central foi introduzido com as características e funções da medula espinal, vias aferentes e eferentes e reflexos medulares. Abordou-se a anatomia do cérebro, ressaltando a importância dos sulcos e os diferentes lobos e suas funções. As diferenças entre cérebro e encéfalo também foram enfatizadas, trazendo as funções básicas do cerebelo e tronco encefálico. Na última parte da aula, os componentes microscópicos foram ressaltados, as principais células do sistema nervoso foram apresentadas, bem como suas principais funções.

Atividade(s) prática(s): duas atividades foram propostas e aplicadas em diferentes momentos.

i. "Reforçando conceitos": para reforçar alguns pontos da aula, os alunos receberam folhas com desenho representativo do encéfalo e medula espinal. Desta forma, ao longo da explanação teórica puderam destacar seus principais constituintes, como por exemplo, a localização dos lobos e substância branca e cinza (Figura 1A).

ii. "A arte da neuroanatomia": foram disponibilizadas massas de modelar de diferentes cores para que os professores pudessem demostrar os conhecimentos adquiridos a partir da aula através de uma forma artística, desenvolvendo modelos de cérebro e células do sistema nervoso (Figura 1B-C). 


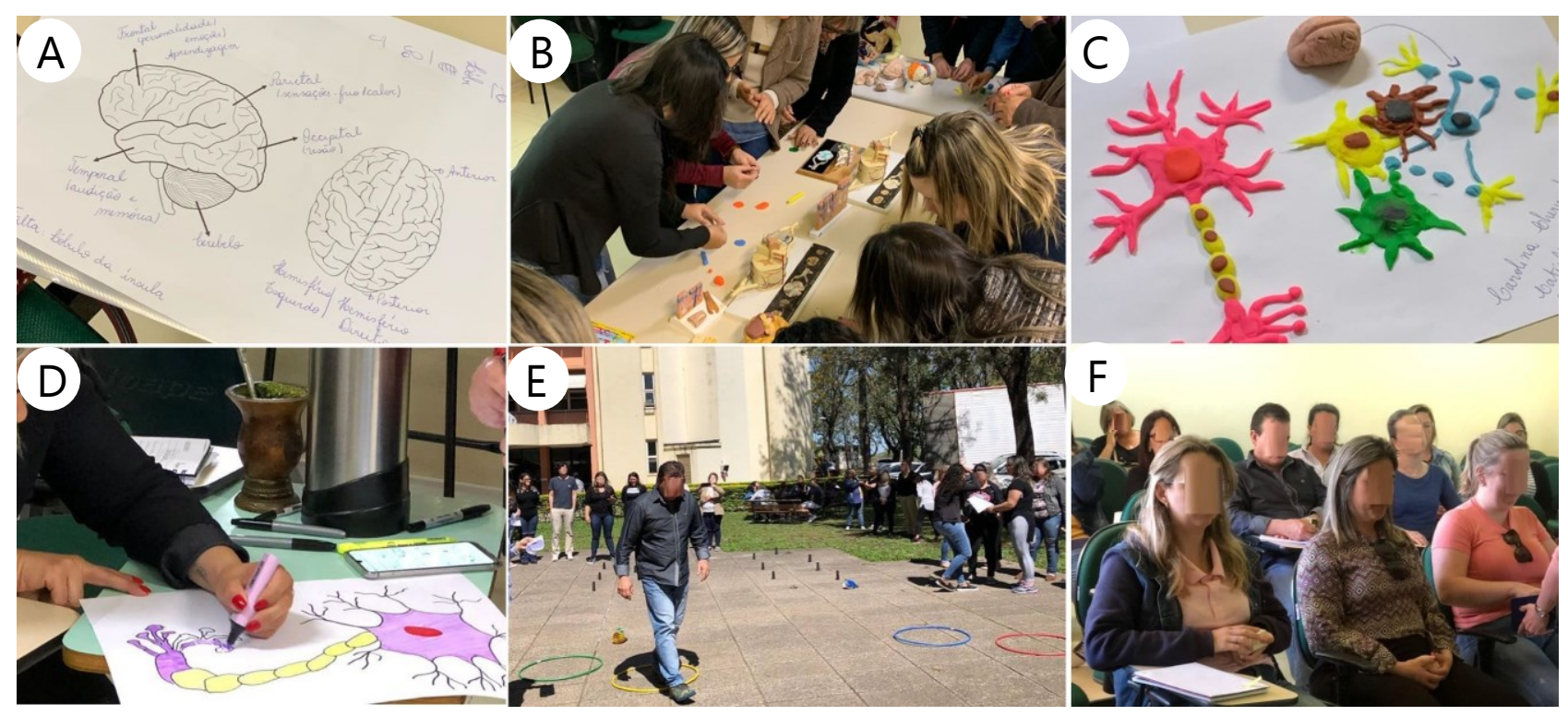

Figura 1. Algumas atividades práticas dos módulos 1 e 2. (A) Atividades práticas da aula "Neuroanatomia": trabalho desenvolvido durante a prática "Reforçando conceitos" e; (B-C) trabalhos desenvolvidos durante a prática "A arte da neuroanatomia". (D) Atividade prática da aula "Neurofisiologia": preparação dos desenhos desenvolvidos na atividade "Entendendo as sinapses". (E) Atividade prática da aula "Fatores que interferem na aprendizagem": professores participando da atividade "Circuito da atenção". (F) Atividades práticas da aula Inovação pedagógica e a neurociência: experiência do sensível (1ºmento pedagógico).

\section{c) Neurofisiologia}

Explanação teórica: foram retomados alguns conceitos sobre neuroanatomia, abordando a organização do sistema nervoso (sistema nervoso central e periférico), as células do sistema nervoso e suas principais funções. Em seguida, enfocou-se a sinalização elétrica dos neurônios, com uma breve explanação sobre o potencial de ação. Discutiu-se, ainda, sobre sinapses químicas e elétricas, além de abordar a importância e atuação dos neurotransmissores. O último ponto tematizado foi sobre as funções complexas do sistema nervoso, através do qual ressaltamos algumas delas, como linguagem e lateralização, leitura e numeracia.

Atividade(s) prática(s): duas atividades foram propostas e aplicadas em diferentes momentos.

i. "Entendendo as sinapses": os alunos foram divididos em grupos responsáveis por desenhar uma das alternativas: (a) neurônio, (b) sinapse macroscópica, (c) sinapse elétrica ou (d) sinapse química. Cada grupo apresentou seu desenho para a turma, explicando as principais características observadas na sua respectiva representação esquemática (Figura 1D).

ii."Qual o neurotransmissor?": através de projeção, foram apresentadas imagens relacionadas à diferentes emoções ou atividades que tendem a liberar maior quantidade de um ou mais neurotransmissor. Os alunos, divididos em grupos, eram estimulados a responder qual ou quais neurotransmissor(es) poderia(m) estar envolvido(s) na ação projetada. Para isso, placas de diferentes cores foram dadas aos grupos, onde cada cor representava um neurotransmissor. 


\section{Módulo 2}

\section{a) Neurobiologia da aprendizagem e memória}

Explanação teórica: nesta aula foram abordados os principais conceitos sobre memória. O conceito de memória foi introduzido e as principais regiões do sistema nervoso envolvidas neste processo foram destacadas - lobos temporal e frontal, que envolvem, respectivamente, as estruturas do hipocampo e córtex pré-frontal. Algumas formas de classificação da memória foram discutidas, como conforme a natureza (explicita e implícita) e o tempo (memória de trabalho, de curta e longa duração). Alguns mecanismos de formação das memórias foram abordados como, por exemplo, o condicionamento clássico postulado por Ivan Pavlov. A aquisição, retenção e demais processos de formação e evocação da memória foram discutidos.

Atividade(s) prática(s): uma atividade foi proposta e aplicada após a explanação teórica.

i. "Neuroquiz": através de projeção, o jogo foi apresentado aos professores, organizados em pequenos grupos. Cada grupo poderia escolher um número exposto na projeção inicial, que corresponderia a uma determinada pergunta relacionada ao tema de aula previamente discutido ou a algum assunto abordado nas aulas anteriores. Em caso de acerto o grupo continuava jogando, em caso de erro, passava a vez para o grupo posterior. As questões eram retomadas e explicadas sempre que necessário, e o objetivo do jogo foi a fixação do conteúdo abordado.

\section{b) Fatores que interferem na aprendizagem}

Explanação teórica: nesta aula foram abordados alguns fatores capazes de interferir na aprendizagem, a citar: emoções, sono, atenção, motivação, contexto e métodos. A escolha baseou-se na aplicação dos mesmos no cotidiano em sala de aula do professor. O primeiro fator mencionado, emoções, foi introduzido, e as principais emoções sentidas pelos seres humanos e as principais áreas envolvidas foram discutidas (hipocampo, amígdala, córtex pré-frontal). Quanto ao sono, foram abordados seus estágios, funções e fatores que podem interferir no seu processo normal, como doenças e uso de medicamentos. Os tipos de atenção (concentrada, alternada, sustentada e seletiva) foram introduzidos e relacionados à capacidade de realizar uma atividade conforme o nível de concentração e seletividade para esta. Outros assuntos como motivação, contexto e métodos de ensino foram ressaltados, procurando sempre relacionar com a atividade pedagógica e o que de mais recente a neurociência traz sobre isto.

Atividade(s) prática(s): uma atividade foi proposta e aplicada após a explanação teórica.

i. "Circuito da atenção": em uma área externa montou-se um circuito com algumas trajetórias e obstáculos (Figura 1E). O objetivo da atividade foi demonstrar que, conforme sua atenção fosse dividida, o tempo de realização do circuito sofreria mudanças. Após organizados em duplas - uma pessoa realizava o trajeto do circuito e seguia as instruções que eram mencionadas por outro colega. Abaixo a descrição da atividade proposta:

$1^{\circ}$ Momento: o circuito deveria ser realizado sem nenhuma dificuldade imposta: passar nos cones em "ziguezague"; andar em linha reta (sobre a linha desenhada no chão); "entrar" no bambolê; andar sobre a linha desenhada no chão até o fim do circuito.

$2^{\circ}$ Momento: o circuito deveria ser realizado da seguinte forma: o "zigue-zague" deveria ser realizado efetuando o seguinte cálculo: 238 - 20 + 50 = 268; a linha reta deveria ser realizada com "bilboquê"; "entrar" no bambolê; andar sobre a linha desenhada no chão. 
$3^{\circ}$ Momento: o circuito deveria ser realizado da seguinte forma: "zigue-zague batendo palmas e resolvendo o seguinte problema: 100/2 + $12-4=58$; a linha reta deveria ser realizada com "bilboquê" e cantando "atirei o pau no gato"; "entrar" no bambolê; andar sobre a linha realizando o cálculo: $20-3-3-3-3=8$.

O tempo de realização do circuito nos três momentos foi cronometrado.

\section{c) Inovação pedagógica e a neurociência}

Explanação teórica: esta aula teve como objetivo refletir sobre a neurociência aplicada à educação em uma perspectiva da inovação pedagógica, considerando práticas educativas, planejadas a partir da metodologia dialética, que, conforme Vasconcellos (2019, p. 1-2), está baseada em três dimensões: (1) Mobilização para o conhecimento (síncrese): momento em que se propôs vivência problematizadora e mobilizadora; (2) Construção do conhecimento (análise): momento pedagógico em que, por meio das atividades problematizadoras, desenvolveram-se diálogos e vivências teórico-práticas, com análise e (re)construção de conhecimentos, estabelecendo relações entre inovação e neurociência na educação; e, (3) Elaboração e expressão da síntese do conhecimento (síntese): momento em que foi possível sintetizar os entendimentos sobre inovação pedagógica e neurociência.

Atividades práticas: para cada momento pedagógico foram proporcionadas práticas reflexivas e criativas.

i. "Primeiro momento pedagógico": no primeiro momento pedagógico, foi vivenciada a experiência do sensível, no qual cada cursista, de olhos fechados, escolheu um objeto de uma caixa que circulou pelo grupo, relacionando-o às abordagens realizadas durante o curso, destacando uma palavra-chave (Figura 1F). Como expressa Damásio (2005), uma "experiência emocional [...] inclui a percepção e identificação do produto, as associações e lembranças que ele ativa, os sentimentos e as emoções que ele evoca, e os julgamentos que ele aciona".

ii. "Segundo momento pedagógico": no segundo momento pedagógico, foi trabalhada a metodologia "estações por rotação", dinamizado em seis diferentes estações (ilhas), em que os participantes, divididos também em seis grupos, foram desafiados a realizar a atividade proposta em cada uma das estações. $\mathrm{Na}$ $1^{\text {a }}$ estação, o grupo de participantes criou uma poesia coletiva sobre a importância das emoções e dos sentimentos no processo ensino-aprendizagem. $\mathrm{Na} 2^{\mathrm{a}}$ estação, cada grupo construiu um acróstico coletivo com palavras significativas relacionadas à expressão "funções executivas". Na $3^{a}$ estação, os participantes elaboraram um texto coletivo crítico-reflexivo com argumentos que relacionaram a categoria da metacognição com a construção do conhecimento. Na $4^{a}$ estação, cada grupo evocou memórias emocionais escolares que foram representadas de forma criativa, usando materiais diversos disponíveis. $\mathrm{Na}$ $5^{\text {a }}$ estação, os participantes assistiram um clipe musical, e a partir desse indicaram conhecimentos, atitudes e valores que envolvem o currículo escolar. $\mathrm{Na} 6^{a}$ estação, cada grupo inventou parte de uma fotonovela sobre a inovação pedagógica, relacionando com conhecimentos de neurociência. A rotação foi concluída quando cada grupo chegou na estação que iniciou e, nesse momento, analisou a construção coletiva e colaborativa da respectiva estação, e socializou três palavras-chave significativas.

iii. "Terceiro momento pedagógico": no terceiro momento pedagógico, foi realizada uma roda de conversa, em que cada participante sistematizou as vivências pedagógicas em uma palavra-chave - memória, lembrança, medo, sentimento, curiosidade e surpresa foram as palavras mais citadas.

\section{Avaliação do curso}

A avaliação do curso foi feita através da aplicação de um questionário inicial (Tabela 2) e final (Tabela 3). Os questionários foram aplicados, respectivamente, no primeiro e último dia do curso. Avaliamos os 
conhecimentos prévios dos professores sobre neurociência, a motivação e as perspectivas acerca do curso e, por fim, verificamos a relevância da aplicação do curso.

\section{Análise dos resultados}

Os resultados foram analisados utilizando o percentual de respostas (\%) ou média e desvio-padrão. As questões abertas foram lidas e categorizadas de acordo com as similaridades das respostas, sendo apresentadas de acordo com sua frequência relativa (\%). Para comparação pré e pós-teste foi utilizado o teste Wilcoxon, considerando significativo $p<0,05$.

\section{Resultados e Discussão}

Dentre os professores inscritos que contemplaram pelo menos $75 \%$ da carga horária total do curso, 27 responderam ao questionário inicial - aplicado no primeiro dia do curso, e 25 responderam ao questionário final - aplicado no último dia do curso. A partir disso, podemos observar que o curso foi bem aceito pelos professores, uma vez que entre o primeiro e segundo módulo, o número de participantes manteve-se praticamente equivalente.

Inicialmente, buscamos compreender o perfil dos professores e o contato prévio com o tema principal do curso, a neurociência. A maioria deles não tinha realizado nenhum curso na área de educação e neurociência até o momento, correspondendo a $74 \%$ dos professores $(n=20$, Figura $2 A)$. Apesar de demonstrar interesse na temática, apenas $11 \%(n=11$, Figura $2 B$ ) afirmou ler sobre neurociência e neuroeducação, sendo a internet a principal fonte de leitura. $\mathrm{O}$ contato com o tema nas redes sociais foi ressaltado por quase todos os professores, destacando-se o Facebook (52\%, n = 14, Figura 2C) e o Instagram (19\%, n = 5, Figura 2C).

Para compreender o conhecimento prévio que os professores acreditavam ter acerca de alguns temas da neurociência pedimos para eles que o quantificassem, classificando seus conhecimentos em uma escala 0 a 10, considerando 0 ruim e 10 excelente. A média e desvio padrão obtidos foram, respectivamente, 1,67 $\pm 2,13$ para o tema "neuroanatomia" (mediana 1,00), 1,96 \pm 2,31 para "neurofisiologia" (mediana 1,0) , 2,04 \pm 2,61 para "neurobiologia da aprendizagem e memória" (mediana 0) e 2,89 \pm 2,87 para "inovação pedagógica e neurociência" (mediana 3). Observamos que conhecimento auto relatado dos professores sobre os diferentes temas variou significativamente dentro da amostra em estudo, considerando os desvios-padrão apresentados. Esta variação pode estar relacionada com as experiências ou contatos prévios que alguns professores tinham com o tema, fazendo com que estes se sentissem mais seguros em qualificar seus conhecimentos, enquanto outros professores não apresentaram a mesma segurança, talvez por ter menos contato prévio com o tema. De qualquer forma, considerando que a escala de conhecimento era de zero (nenhum conhecimento) até dez (muito conhecimento), destacamos que houve apenas um professor que considerou seu conhecimento no nível 8 em todas as áreas, e três que consideraram nível 5, os demais atribuíram valores abaixo de 5.

Ainda, no questionário inicial, quando perguntamos "O que você entende por neurociência?", 44\% (n = 12) relatou que consiste no estudo do cérebro e, apenas $5 \%(n=5)$ ressaltou o estudo do sistema nervoso resposta mais coerente, uma vez que abrange outras regiões além do cérebro (Grossi et al., 2015). Desta forma observamos a carência de conhecimento no que compete ao conceito de neurociência bem como de temas relacionados a esta área, o que enfatiza a importância de cursos de formação continuada à professores que abordem esta temática. 
A Já fez algum curso na área de educação e neurociência?

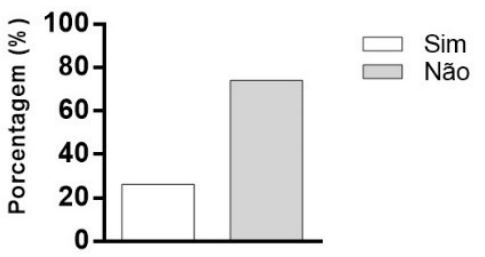

B Costuma ler sobre neurociência e educação?

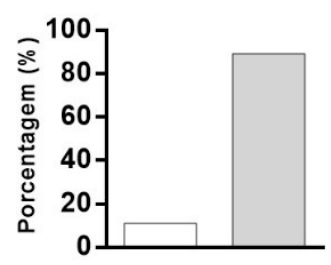

C Tem contato sobre temas relacionados à neurociência pelas redes sociais?

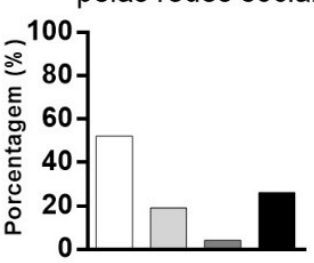

$\square$ Sim, por Facebook

$\square$ Sim, por instagram

$\square$ Nunca teve contato

- Outro

Figura 2. Contato prévio com a neurociência. Respostas para as questões (A) "Já fez algum curso na área de educação e neurociência?" (B) "Costuma ler sobre neurociência e educação?" (C) "Tem contato sobre temas relacionados à neurociência pelas redes sociais?". Expresso em percentual (\%), n=27.

O conhecimento da neurociência proporciona o entendimento das regiões e estruturas cerebrais, bem como suas respectivas funções, além dos aspectos neurobiológicos que englobam as células nervosas e os processos químicos e fisiológicos importantes para a cognição (Ventura, 2010). Cunha (2015) ressalta que entender o funcionamento do cérebro e como ele aprende é necessário para o desenvolvimento de estratégias pedagógicas de ensino que supram as necessidades e dificuldades de aprendizagem de cada aluno.

Quanto às perspectivas acerca do curso, $48 \%(n=13)$ dos professores enfatizou a importância de estudar neurociência aplicada à educação para melhor compreensão dos processos de aprendizagem. A possibilidade de adquirir conhecimento na área foi a maior motivação para a inscrição no curso, contemplando $48 \%$ das respostas $(n=13)$, outras respostas como interesse na temática, curiosidade e importância para a formação e prática docente também foram ressaltadas.

O conhecimento da neurociência pode influenciar diretamente no processo de formação (Grossi et al., 2014), pois seu entendimento possibilita contemplar as particularidades de cada indivíduo (Sousa et al., 2017). Entretanto, esta temática ainda não se faz presente na maioria dos cursos de formação pedagógica de professores - principais responsáveis pela mediação e construção do conhecimento em nossa sociedade (Grossi et al., 2014). Com isso, é importante que o processo de formação docente esteja em constante desenvolvimento (Carvalho, 2010), sendo indispensável a atualização contínua em temáticas que possam aprimorar os métodos de ensino (Sousa et al., 2017).

Foi consenso entre os professores que o curso ministrado atendeu a suas expectativas, trazendo conceitos básicos da neurociência, e a importância desse conhecimento na prática pedagógica. Segundo Grossi e colaboradores (2014), uma vez compreendido pelos docentes que cada indivíduo utiliza o cérebro de uma maneira diferente para pensar e aprender, é possível facilitar o processo de ensino-aprendizagem, o que influencia diretamente para o desenvolvimento cognitivo de seus alunos. Além disso, é fundamental que os docentes tenham capacidade de constatar, na sala de aula, possíveis alterações no sistema nervoso, situações emocionais, psicológicas e outras, que possam gerar dificuldades, para que assim seja possível adequar o processo de ensino, atendendo às necessidades educativas de cada indivíduo, permitindo seu aprendizado (Grossi et al., 2015).

Dentre os pontos positivos do curso, a aquisição de novos conhecimentos e o dinamismo das aulas foram os mais citados, correspondendo a um percentual de $28 \%$ cada $(n=7$, Figura $3 \mathrm{~A})$. A maioria $(48 \%, n=12$, Figura 3B) não citou nenhum ponto negativo do curso, e a carga horária curta foi o mais citado $(28 \%, n=7$, Figura 3B). Outros pontos também foram abordados como mostrado na Figura 3. 


\section{A Pontos positivos do curso}

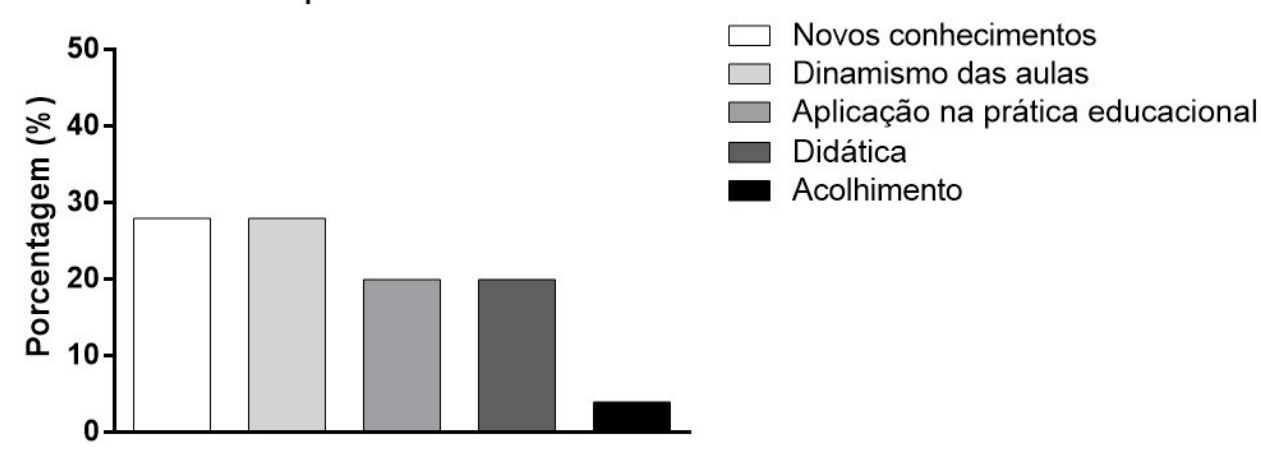

\section{B Pontos negativos do curso}

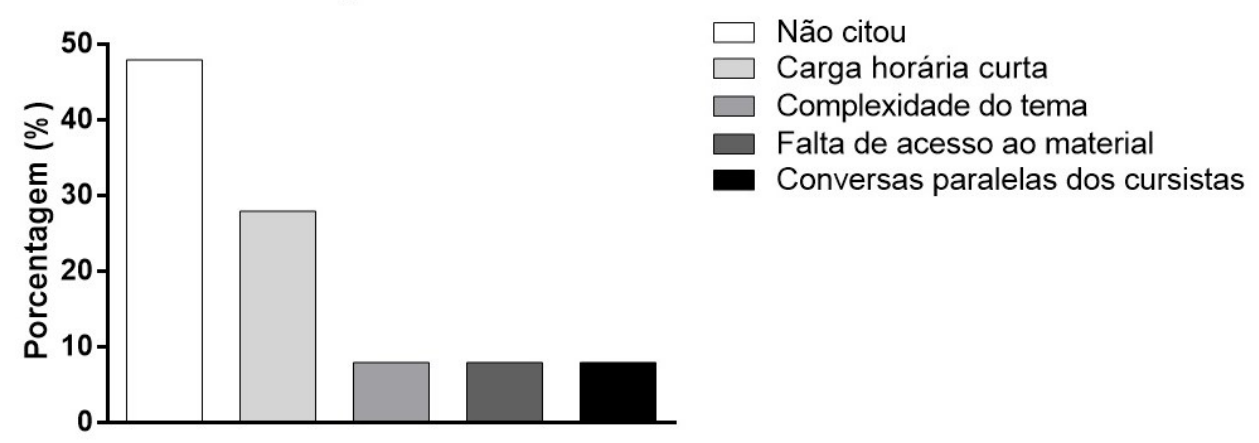

Figura 3. Pontos positivos (A) e negativos (B) atribuídos pelos professores acerca do VIII Curso de Neurociência Aplicada à Educação. Expresso em percentual (\%), $n=25$.

Para avaliar se o curso auxiliou na aquisição de conhecimento acerca dos principais temas abordados durante os dois módulos, solicitamos novamente a atribuição do nível de conhecimento autopercebido, considerando uma escala de 0 a 10, sendo 0 ruim e 10 excelente, como solicitado no questionário inicial. Desta vez, a média e desvio padrão obtidos foram, respectivamente, 6,96 $\pm 2,05$ para o tema "neuroanatomia" (mediana 7), 7,20 \pm 2,06 para "neurofisiologia" (mediana 7), 8,16 \pm 1,55 para "neurobiologia da aprendizagem e memória" (mediana 7), e 8,24 \pm 1,61 para "inovação pedagógica e neurociência" (mediana 8). Houve, portanto, um aumento expressivo do nível de conhecimento acerca destes temas atribuídos pelos professores, o que indica que a expectativa inicial de aquisição de conhecimento, foi de fato alcançada. Podemos observar esta diferença, estatisticamente mais alta, na Figura 4, que compara a média do nível de conhecimento autoatribuído pelos professores no período pré e pós-curso.

Foi unanimidade entre os professores afirmar que seu entendimento sobre neurociência melhorou após a realização do curso. Estes dados corroboram com a citação de um dos docentes:

"Neurociência trata o funcionamento de todo nosso sistema. A realização do curso melhorou muito meu entendimento, principalmente com relação aos "termos técnicos". 


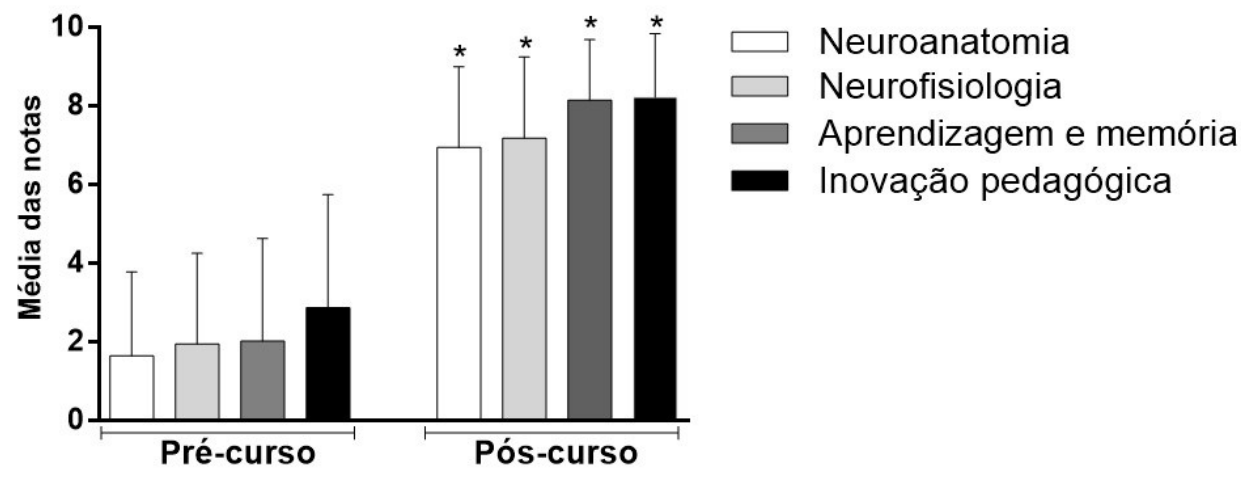

Figura 4. Média das notas do nível de conhecimento dos professores acerca dos temas "neuroanatomia", "neurofisiologia", "neurobiologia da aprendizagem e memória" e "inovação pedagógica e neurociência" précurso e pós-curso. Expresso em média \pm desvio padrão, $\mathrm{n}=25-27 .{ }^{*}=p<0,05$, teste Wilcoxon (pré-curso x póscurso).

Os professores também afirmam que os conhecimentos a partir do curso irão impactar na sua prática docente. Dentre as justificativas, alguns professores ressaltam a importância de saber como ocorre os processos de formação e persistência da memória, assim como a interferência de alguns fatores sobre o aprendizado, como fatores biológicos e sociais, emoções e as particularidades individuais de cada aluno. A seguir destacamos algumas destas falas:

"Como é importante conhecer o funcionamento do cérebro e o que isso interfere na vida de cada ser humano".

"Certamente os conhecimentos irão influenciar na maneira que vou atuar dentro da sala de aula e a maneira que vou lidar com as dificuldades de aprendizagens de cada aluno".

"Trabalhamos numa educação inclusiva e com o curso ressignificamos essa prática levando em consideração as particularidades de cada indivíduo".

Para que seja possível ofertar uma educação com qualidade e que atenda as dificuldades de cada aluno é importante compreender que cada indivíduo possui caminhos que auxiliam sua aprendizagem (Cunha, 2015). Nesse sentido, a aprendizagem se resume em situações que envolvem o ambiente, emoções, aspectos sociais, físicos e psicológicos, sendo importante contextualizar uma educação que permita a postura ativa do aluno como construtor do seu próprio conhecimento (Souza \& Gomes, 2015).

Aliar os estímulos ambientais às vivências dos alunos para favorecer a aprendizagem é fundamental (Dorneles et. al, 2012). Uma boa condução do processo de ensinar e aprender contribui para o processo de ativação das áreas corticais, estimulando a neuroplasticidade, fazendo com o que o cérebro seja constantemente estimulado, o que possibilita a interação dos estímulos ambientais com as experiências do aluno, auxiliando na aprendizagem (Dorneles et. al, 2012).

Quando perguntamos "O que você mais gostou no curso?" a maioria dos professores $(40 \%, n=10)$ citou que as atividades práticas associadas ao conteúdo teórico foram essenciais (Figura $5 \mathrm{~A}$ ). Alguns professores (24\%, $\mathrm{n}=6$ ) também ressaltaram a possibilidade de entendimento sobre temas da neurociência, destacando, por exemplo, os processos de aprendizagem e neurobiologia da memória e sua relação com a prática docente (Figura $5 \mathrm{~A})$. O mesmo percentual $(24 \%, n=6)$ não soube citar apenas um ponto no qual mais gostou, indicando sua satisfação em todos os pontos do curso; um dos professores ressalva: "[Gostei] De tudo, gostaria até de fazer de novo". Além disso, a correlação entre uma aula e outra também foi citada ( $12 \%, n=3)$, como indica 
um dos professores: "[Gostei] Dos dois módulos, pois um complementou o outro e esclareceu questões da memória e aprendizagem."

A abordagem prática estimula o desenvolvimento de habilidades diversas como coordenação, expressão corporal, criatividade e iniciativa promovendo forte interação do indivíduo com o ambiente (Cunha, 2015). A compreensão de como o cérebro atua fornece condições mais adequadas para que o professor possa estimular a motivação de seus alunos em sala de aula (Carvalho, 2010), problematizando situações e permitindo a busca por respostas em um ambiente lúdico e desafiador, explorando suas capacidades mais profundas (Sacchetto, 2011). Em nosso curso, enfatizamos a importância de retomar o aprendizado anterior e correlacionar a abordagem teórica com atividades práticas lúdicas e criativas que estimulem o pensamento dos alunos a respeito dos temas abordados em aula, reativando os circuitos neurais responsáveis pela formação da memória e do aprendizado, favorecendo a consolidação e persistência do mesmo.

Dentre os maiores aprendizados adquiridos a partir do curso (Figura 5B), os processos referentes à aprendizagem e memória são os mais citados pelos professores $(40 \%, \mathrm{n}=10)$. A relação da temática abordada com a prática pedagógica também foi citada com frequência entre os professores $(36 \%, n=9)$, seguida do entendimento do funcionamento do cérebro $(16 \%, n=4)$. Aqui destacamos algumas citações dos professores:

"O conceito de neuroplasticidade; que aprender ocupa espaço e que não existe idade para o aprendizado."

"Que as lembranças podem ser modificadas; que há a neuroplasticidade de nosso cérebro; que as experiências influenciam na aprendizagem".

\section{A O que você mais gostou no curso?}

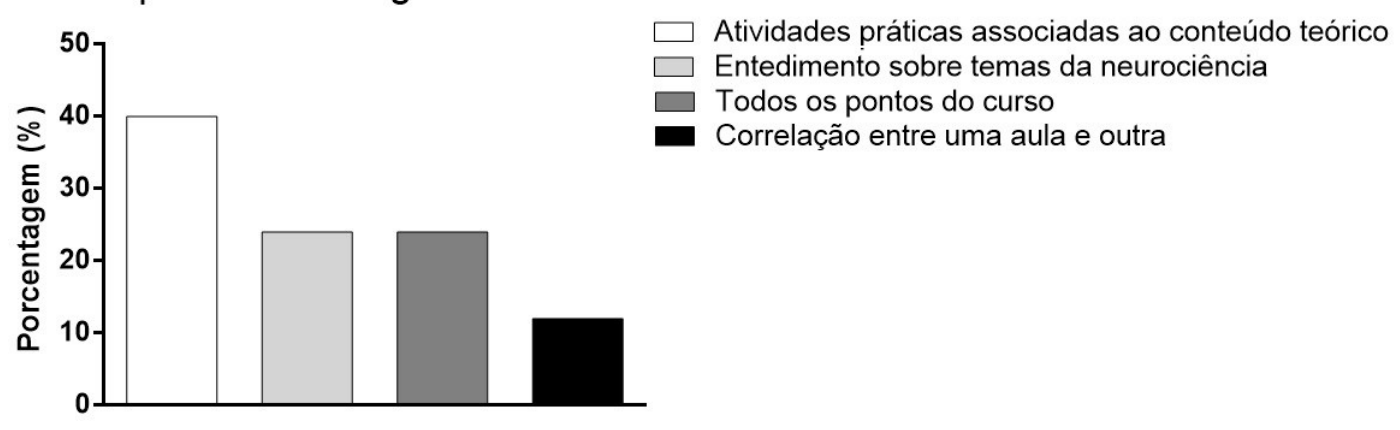

B Qual o maior aprendizado adquirido

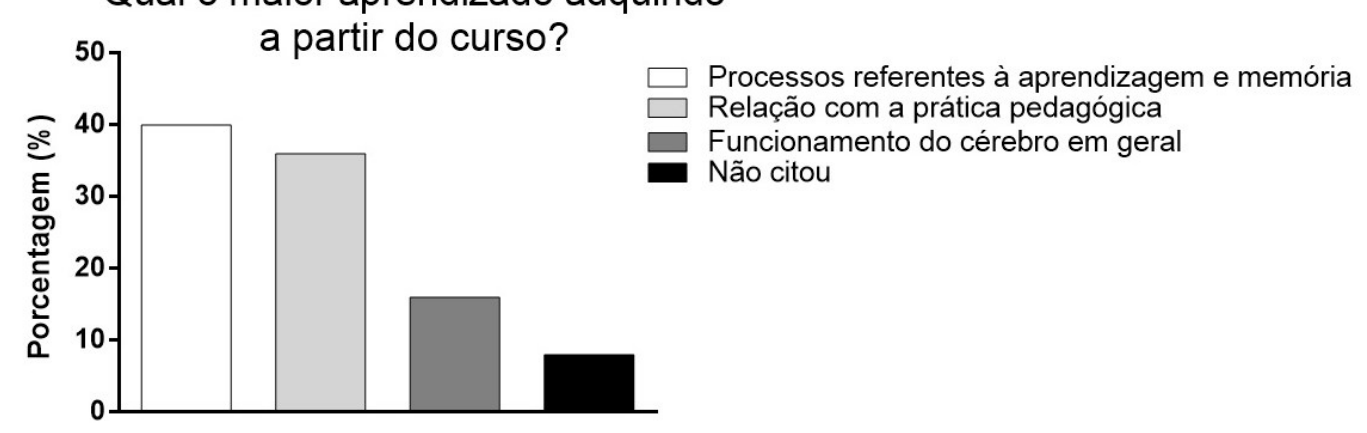

Figura 5. A. Pontos que os professores mais gostaram no VIII Curso de Neurociência Aplicada à Educação. B. Maiores aprendizados adquiridos a partir do VIII Curso de Neurociência Aplicada à Educação. Expresso em percentual (\%), $\mathrm{n}=25$. 
Já se sabe que cursos de formação continuada em neuroeducação são de fundamental importância para ampliar o conhecimento sobre determinada temática, o que possibilita a atualização contínua do profissional (Filipin et al., 2016). Aqui, percebemos o interesse dos professores em buscar de um melhor entendimento sobre neurociência e sua contribuição para a educação. Nossos achados corroboram com o estudo de Filipin et al. (2017), que observou a compreensão por parte dos professores sobre a relação da neurociência e a prática docente.

Uma das abordagens destacadas foi a percepção de como o cérebro armazena as informações que são recebidas, compactuando com os processos de aquisição e retenção da memória que são a base para o aprendizado - uma vez que a memória pode ser vista como o conjunto de processos neurobiológicos e neuropsicológicos que permitem a aprendizagem (Lent, 2001). Nesse sentido, é fundamental que os educadores conheçam o cérebro e suas estruturas como interface da aprendizagem, sendo esse um campo de contínua exploração (Sousa et al., 2017).

Ao despertar no aluno certa curiosidade, temos um maior engajamento do mesmo em querer participar, o que pode ser chamado de motivação, a qual possui um papel fundamental e facilitador da aprendizagem. Quanto maior a possibilidade de interagir, comunicar, criar, aprender e até mesmo ousar, maior o interesse e a retenção do conteúdo, consequentemente, maior a aprendizagem (Sacchetto, 2011). Em nosso curso, aplicamos algumas atividades práticas relacionadas aos conteúdos teóricos como exemplos que podem ser utilizados e/ou adaptados posteriormente pelos professores, em sala de aula. Outros estudos trazem modelos de metodologias práticas, lúdicas e eficazes que podem ser reaplicadas em sala de aula, como por exemplo, o "Circuito Sensorial" realizado por Gonçalves e colaboradores (2016); "Neurogame" desenvolvido por Lima e colaboradores (2017); seminários didáticos (Barros et al., 2012), entre outros, lembrando que o foco principal é a motivação do aluno em participar da atividade para que assim, auxilie seu processo de aprendizagem.

Quando solicitados para atribuir uma nota de 0 (ruim) a 10 (excelente) para o curso, a média atribuída foi de $9,92 \pm 0,28$, o que contribui com os dados aqui citados sobre a satisfação a partir do curso. Dentre as sugestões mais frequentes para as próximas edições destacam-se o envio prévio das aulas (slides), com intuito de facilitar as anotações durante a exposição do conteúdo, o aumento da carga horária do curso para que mais temas sobre neurociência possam ser abordados - sendo doenças e transtornos do sistema nervoso o mais pedido, uma vez que alguns professores atuam na Educação Especial ou possuem alunos com necessidades especiais em sua sala de aula.

Adicionalmente, ações como esta são benéficas não só para os cursistas, mas também para todos aqueles que auxiliam na promoção do curso - que abrange estudantes de graduação e pós-graduação. Estas atividades permitem que os estudantes se envolvam desde a organização até a ministração das aulas, permitindo-os obter novos aprendizados, além dos que são oferecidos em sala de aula.

\section{Considerações finais}

A realização do VIII Curso de Neurociência Aplicada à Educação foi de suma importância para a formação continuada dos professores. Os participantes demonstraram interesse durante todas as aulas ministradas, gerando discussões importantes e momentos de interação entre os ministrantes e cursistas. Além disso, as atividades práticas propostas tiveram um bom aceite, auxiliando ainda mais no processo de aquisição dos conhecimentos propostos, fazendo com que os professores participassem de forma ativa durante vários momentos das aulas. Os dados aqui apresentados confirmam estas observações, segundo as quais os participantes demonstraram-se satisfeitos com a didática proposta. Consideramos que foi atingido o objetivo do curso, que consiste em promover a formação de professores da Educação Básica em neurociência. Ainda, cabe ressaltar a importância na formação dos alunos que auxiliaram na organização do curso e ministração 
das aulas, uma vez que, portanto, obtivemos um aprendizado mútuo, proporcionando um momento de troca de conhecimentos entre os cursistas e os promotores desta ação.

\section{Contribuição de cada autor}

KRL realizou a análise dos dados. KRL, LFL, NMS, RMF e EMBM participaram da escrita do artigo. PBMC atuou como coordenador e orientador dos bolsistas e realizou a revisão final. Todos os autores analisaram, discutiram os dados e leram e aprovaram a versão final do manuscrito.

\section{Nota}

1 Facebook. https://www.facebook.com/gpfis.neurociencianaescola, Instagram: https://www.instagram.com/ programapopneuro/

\section{Referências}

Barros, W. M., W., Alves, N., de Menezes, J. R., \& Mello-Carpes, P. B. (2012). Seminários didáticos: Ferramenta de aproximação das disciplinas básicas com a prática profissional. Revista Ciência em Extensão, 8(3), 130.

Blakemore, S. J., \& Frith, U. (2000). The implications of recent developments in neuroscience for research on teaching and learning. Journal of The Institute of Training \& Occupational Learning, 2(2), 3-42.

Bulgraen, V. C. (2010). O papel do professor e sua mediação nos processos de elaboração do conhecimento. Revista Conteúdo, 1(4), 30-38.

Cardoso, M., \& Queiroz, S. (2019). As contribuições da neurociência para a educação e a formação de professores: Um diálogo necessário. Cadernos da Pedagogia, 12(24), 30-47.

Carvalho, F. (2010). Neurociências e educação: Uma articulação necessária na formação docente. Trabalho, Educação e Saúde, 8(3), 537-550.

Cunha, P. A. F. (2015). Neurociência e educação: A estimulação cognitiva como possibilidade de intervenção na educação inclusiva [Monografia de Especialização]. Universidade de Brasília, UNB. Brasília.

Damásio, A. R. (1994). O erro de Descartes: Emoção, razão e o cérebro humano. São Paulo. Companhia das Letras.

Dorneles, C., Cardoso, A., \& Carvalho, F. (2012). A educação de jovens e adultos na perspectiva das neurociências. Revista Psicopedagogia, 29(89), 244-255.

Escribano, C. L. (2007). Contribuciones de la neurociencia al diagnóstico y tratamento educativo de la dislexia deldesarrollo. Revista de Neurología, 44(3), 173-180.

Filipin, G., Casarotto, F., Mello-Carpes, P., \& Vargas, L. (2017). Formação continuada em Neuroeducação: Percepção de professores sobre a neurociência e sua importância para a educação. Experiência: Revista Científica de Extensão, 3(1), 40-57.

Fonseca, V. (1988). Psicomotricidade. 2. ed. São Paulo: Martins Fontes.

Gonçalves, R.; Mello, E. M. B., \& Mello-Carpes, P. B. (2016). Oficina" Circuito Sensorial" como metodologia utilizada na formação continuada de professores de ciências. Revista Ciência em Extensão, 12(1), 6-13.

Grossi, M. G. R., Grossi, V. G. R., Souza, J. R. L. M., \& Santos, E. D. (2014). Uma reflexão sobre a neurociência e os padrões de aprendizagem: A importância de perceber as diferenças. Debates em Educação, 6(12), 93.

Grossi, M. G. R., Leroy, F. S., \& De Almeida, R. B. S. (2015). Neurociência: Contribuições e experiências nos diversos tipos de aprendizado. Abakós, 4(1), 34-50.

Lent. (2001). Cem bilhões de neurônios: Conceitos fundamentais de neurociência. São Paulo: Atheneu.

Lima, K. R., Garcia, A., Filipin, G., Vargas, L. S., \& Mello-Carpes, P. B. (2017). Trabalhando conceitos da neurociência na escola: saúde do cérebro e plasticidade cerebral. Revista Ciência em Extensão, 13(2), 71-82. 
Relvas, M. P. (2012). Neurociência na prática pedagógica. Rio de Janeiro: Wak Editora.

Ricoy, M. C., \& Couto, M. J. V. S. (2011). As TIC no ensino secundário na matemática em Portugal: A perspectiva dos professores. Revista Latinoamericana de Investigación em Matemática Educativa - RELIME, 14, 95-119.

Sacchetto, K. K., Madaschi, V., Barbosa, G. H. L., Silva, P. L., Silva, R. C. T., Cruz, B. T., \& Souza-Silva, F. J. R. (2011). O ambiente lúdico como fator motivacional na aprendizagem escolar. Cadernos de Pós-Graduação em Distúrbios do Desenvolvimento, 11(1), 28-36.

Silva, F., \& Morino, C. (2012). A importância das neurociências na formação de professores. Momento Diálogos em Educação, 21(1), 29.

Sousa, A., \& Alves, R. (2017). A neurociência na formação dos educadores e sua contribuição no processo de aprendizagem. Revista Psicopedagogia, 34(105), 320-331.

Souza, M. C., \& Gomes, C. (2015). Neurociência e o déficit intelectual: Aportes para a ação pedagógica. Revista Psicopedagogia, 32(97), 104-114.

Vasconcellos, C. D. S. (1992). Metodologia dialética em sala de aula. Revista de Educação AEC, 21(83), 28-55.

Ventura, D. (2010). Um retrato da área de Neurociência e comportamento no Brasil. Psicologia: Teoria e Pesquisa, 26(spe), 123-129.

Como citar este artigo:

Lima, K. R., Lopes, L. F., Soares, N. M., Franco, R., Mello, E. M. B., \& Mello-Carpes, P. B. (2020). Formação continuada em neurociência: Percepções de professores da educação básica. Revista Brasileira de Extensão Universitária, 11(3), 361-376. https:// periodicos.uffs.edu.br/index.php/RBE M.U/article/view/11512/pdf 